\title{
RANCANG BANGUN GAME THE FARMER FEED ANIMALS MENGGUNAKAN METODE FINITE STATE MACHINE
}

\author{
Yusuf Wahid Ramadan \\ Program Studi Teknik Informatika S1, Fakultas Teknologi Industri \\ Institut Teknologi Nasional Malang, Jalan Raya Karanglo km 2 Malang, Indonesia \\ yusuframadan328@gmail.com
}

\begin{abstract}
ABSTRAK
Game genre adventure merupakan game petualangan fokus pada pemecahan teka-teki dalam kerangka naratif, umumnya dengan sedikit atau tanpa elemen aksi. Nama-nama populer lainnya untuk genre ini adalah "petualangan grafis" atau "petualangan titik-dan-klik", tetapi ini hanya mewakili sebagian dari rentang permainan yang jauh lebih luas dan beragam.

Dalam perancangan game ini menggunakan aplikasi sofware Unity 3D, Penulis dalam membuat game ini menerapkan metode kecerdasan buatan Algoritma Finite State Machine untuk merancang perilaku musuh. Penerapan metode Finite State Machine di gunakan pada proses alur kontrol permainan yang terdiri dari 3 level yang mana pemain menyelesaikan setiap level untuk dapat melanjutkan ke level selanjutnya.

Sistem menunjukkan bahwa game The Farmer Feed Animals dapat berjalan dengan baik minimal pada Windows 7, Windows 8, dan Windows 10. Fungsi yang terdapat Finite State Machine berjalan dengan baik dan sesuai, dan terdapat fungsi enemy follow yang gagal karena musuh tidak akan mengejar dan tetap di posisi output-nya.Semua tombol yang pada game sesuai dengan outputnya.Berdasarkan hasil pengujian koresponden yang menyatakan baik sebanyak 14\%.yang menyatakan baik sekali $50 \%$ dan yang menyatakan cukup $36 \%$.
\end{abstract}

Kata kunci : Game, Unity3D, Algoritma Finite State Machine, Player

\section{PENDAHULUAN}

\subsection{Latar Belakang}

Dunia anak adalah dunia bermain, pada dasarnya membutuhkan dunia yang penuh kebebasan dan kegembiraan. Komputer dapat memberikan sarana belajar yang positif dengan pendekatan sesuai tahap perkembangan anak dalam belajar. Pembelajaran melalui permainan mampu memberikan beberapa keuntungan. Pertama, apa yang dipelajarai oleh peserta didik tidak hanya berupa pengetahuan akal semata, melainkan benar-benar dialami secara nyata, pengalaman yang demikianlah yang sulit dilupakan. Kedua, pelajaran yang diberikan dapat diterima secara menyenangkan karena terkait dengan sifat dasar permainan yang menghibur dan menggembirakan. Ketiga, karena permaianan itu menyenangkan, bermain sekaligus membangkitkan minat yang besar bagi peserta didik akan topik tertentu. Permainan yang di desain dengan baik akan mengembangkan keterampilan peserta didik dalam hal tersebut karena peserta didik menyukai hal tersebut. (Yusuf, 2019).

\subsection{Rumusan Masalah}

Berdasarkan latar belakang masalah diatas, dapat dirumuskan permasalahan yang akan dibahas adalah :

1. Bagaimana menerapkan metode Finite State Machine sebagai kecerdasan buatan pada game The Farmer Feed Animals ?

2. Bagaimana membuat game 2D The Farmer Feed Animals dengan menggunakan Unity 3D?

\subsection{Tujuan Penelitian}

Adapun yang menjadi tujuan penulisan dalam proposal ini adalah sebagai berikut :

1. Merancang suatu game the farmer feed animals sebagai kecerdasan buatan untuk memacu kecepatan strategi untuk menemukan makanan pada hewan dalam game.

2. Membuat Game 2D The Farmer Feed Animals dengan Unity $3 D$

\subsection{Batasan Masalah}

Dalam penyusunan laporan agar menjadi sistematis yang mudah dimengerti, maka akan diterapkan beberapa batasan masalah. Adapun batasan masalah ini meliputi : 
1. Pada penelitian ini hanya mengembangkan algoritma pemrograman sesuai dengan metode finite state Machine.

2. Bahasa pemrograman yang digunakan untuk mengembangkan sistem adalah bahasa C\# pada tools Unity.

3. Karakter pada game the farmer feed animals ini dibuat menggunakan software Corel Draw X7.

4. Game The Farmer Feed Animals ini hanya dapat dimainkan pada PC (berbasis dekstop).

5. Target pengguna dari sistem yang dikembangkan adalah untuk anak - anak dengan pengetahuan penggunaan aplikasi komputer yang cukup dengan usia 7-10 tahun.

6. Game the farmer feed animals ini hanya dapat dimainkan oleh satu pemain (single player).

7. Karakter pada game the farmer feed animals ini adalah explores.

8. Game terdiri dari 3 level yang mana pemain menyelesaikan setiap level untuk dapat melanjutkan ke level berikutnya.

\section{TINJAUAN PUSTAKA}

\subsection{Penelitian Terkait}

Game adalah sebuah sistem dimana pemain tersebut terlibat dalam konflik buatan, disini pemain berinteraksi dengan sistem dan merekayasa game dalam kecerdasan buatan, dalam game terdapat peraturan yang bertujuan untuk membatasi perilaku pemain. Salah satu tujuan dari pembuatan game adalah untuk menghibur, game kebanyakan disukai oleh anak - anak hingga orang dewasa. (Marlina, 2015). Edukasi terhadap peran masyarakat tidak hanya dilakukan pada kaum dewasa saja namun juga perlu ditanamkan sejak dini kepada generasi penerus yaitu anak-anak. Dalam setiap game terdapat peraturan yang berbeda - beda untuk memulai permainannya sehingga membuat jenis game semakin bervariasi. Karena salah satu fungsi game sebagai penghilang stress atau rasa jenuh maka hampir setiap orang senang bermain game baik anak kecil, remaja maupun dewasa, mungkin hanya berbeda dari jenis game yang dimainkannya saja. (Ivan, 2013). Teori permainan pertama kali dikemukakan oleh sekelompok ahli Matematika pada tahun 1944. John von Neumann and Oskar Morgenstern menyatakan bahwa permainan terdiri atas sekumpulan peraturan yang membangun situasi bersaing dari dua sampai beberapa orang atau kelompok dengan memilih strategi yang dibangun untuk memaksimalkan kemenangan sendiri ataupun untuk meminimalkan kemenangan lawan (Neumann dkk, 1953).

\subsection{Games}

Game adalah Salah satu hiburan yang berbentuk multimedia yang di buat menarik agar pemain bisa tidak jenuh dalam bermain game sehingga adanya kesenganan dalam batin. Bermain game merupakan hiburan semata untuk memuaskan kesenangan ketika bosan dengan pekerjaan, tugas dan lain-lain. (Marlina, 2015)

Dalam game petualangan pemain diharapkan bisa menganalisa maupun menyimpulkan rangkaian peristiwa dan percakapan, dan menemukan daya fikir siswa. yaitu menemukan pemahaman cara bermain game dengan benar agar bisa melanjutkan ke tahap selanjutnya (Antonius, 2011)

\section{DESAIN DAN PENELITIAN}

\subsection{Perancanangan Struktur Menu Game}

Perancang struktur menu adalah perancangan tata urutan menu dari game the farmer feed animals.

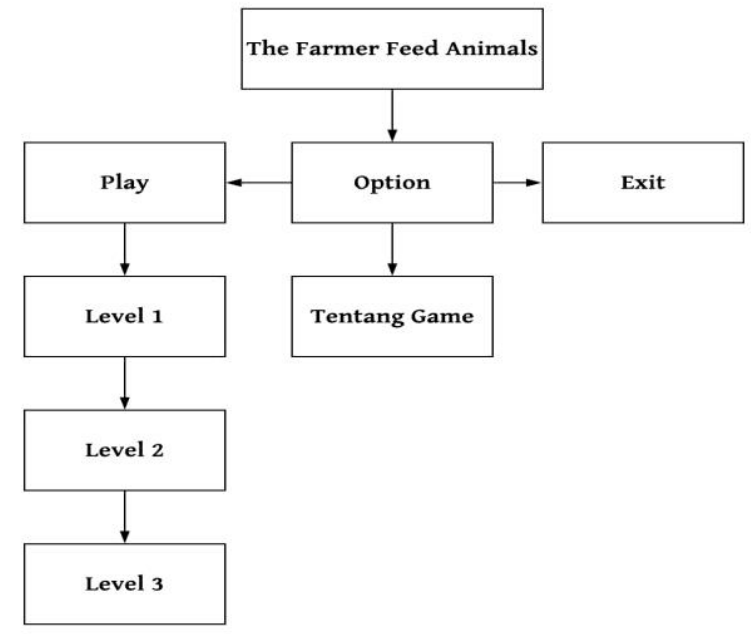

Gambar 3.1 Struktur Menu Game

\subsection{Perancangan Alur Game}

Perancangan alur game berfungsi untuk mengetahui alur proses dari alur program di mulai dari start program hinnga end

\subsection{Peracangan Diagram finite state machine}

Alur metode FSM secara umum yang terdapat pada setiap makanan yang berada di setiap game the farmer feed animals 


\begin{tabular}{|l|l|l|}
\hline No & \multicolumn{1}{|c|}{ Keterangan } \\
\hline 1 & \multicolumn{1}{|c|}{ Karakter } & \multicolumn{1}{|c|}{ Karakter utama game Player Farmer. } \\
\hline 2 & $\begin{array}{l}\text { Merupakan karakter animals yang ada pada } \\
\text { etiap level dan karakter ini akan menerima } \\
\text { makanan dari karakter petani yang telah } \\
\text { ditentukan. }\end{array}$ \\
\hline 4 & $\begin{array}{l}\text { Merupakan karakter penghalang yang harus } \\
\text { dilewati agar dapat mudah menyelesaikannya. }\end{array}$ & $\begin{array}{l}\text { Merupakan item makanan tersembunyi yang } \\
\text { harus ditemukan di setiap levelnya. }\end{array}$ \\
\hline 5 & & $\begin{array}{l}\text { Merupakan rumah jika petani sudah } \\
\text { menyelesaikan semua misi. }\end{array}$ \\
\hline
\end{tabular}

\subsection{Perancangan Diagram FSM}

Pada game ini menggunakan dasar penemuan yang bertujuan untuk menentukan langkah yang akan diambil player. Penerapan algoritma finite state Machine perlu dpersiapkan keadaan, kejadian, dan aksi. Keadaan adalah apa yang dialami karakter. Kejadian adalah kondisi dimana karakter sesuai dengan perintah yang ada pada game. Aksi merupakan hal yang akan dilakukan karakter saat memenuhi sebuah kondisi. Adapun gambar flowchart penerapan metode finite state Machine untuk penjelasan terkait pada game the farmer feed animals

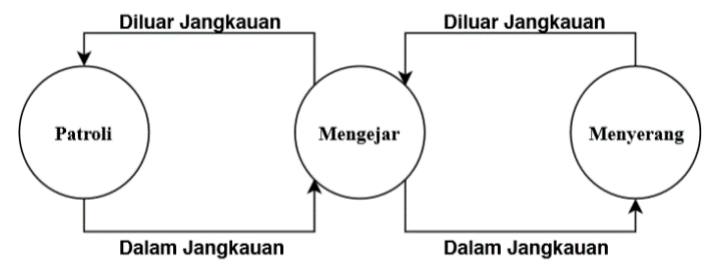

Gambar 3.12 Diagram finite state machine

\section{IMPLEMENTASI DAN PENGUJIAN \\ 4.1 Tampilan Menu Utama}

Tampilan menu utama adalah tampilan awal yang muncul pada saat membuka game the farmer feed animals. Pada tampilan ini berisi tombol play, untuk mulai game, tombol option berisi petunjuk cara memainkan game, exit untuk keluar dari game.adapun desain game menu utama seperti pada Gambar ini 4.1

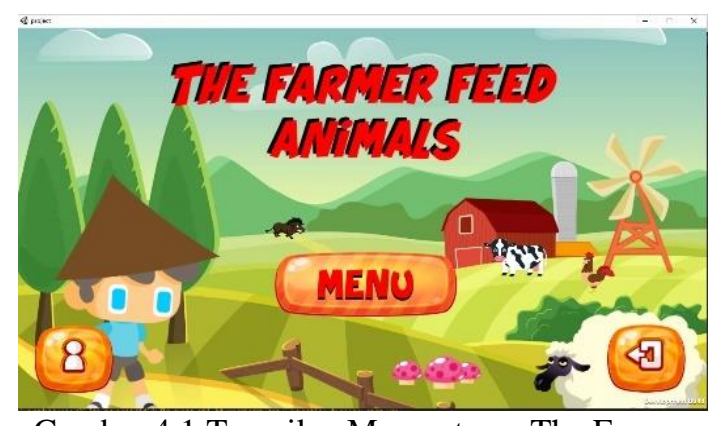

Gambar 4.1 Tampilan Menu utama The Farmer Feed Animals

\subsection{Tampilan Menu Options}

Tampilan menu Play adalah tampilan menu untuk memulai permainan pada game the farmer feed animals, tampilan menu pengaturan cara bermain seperti pada gambar 4.2 


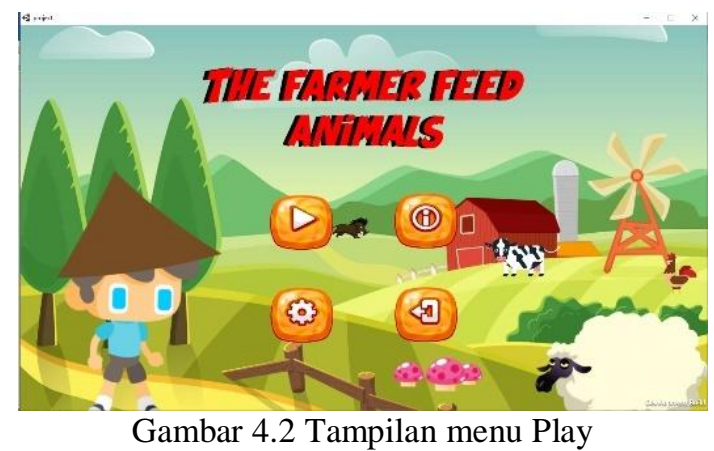

\subsection{Tampilan Menu Options}

Tampilan menu Options merupakan petunjuk tentang game bagaimana dapat menyelesaikan setiap level ditunjukkan pada Gambar 4.3

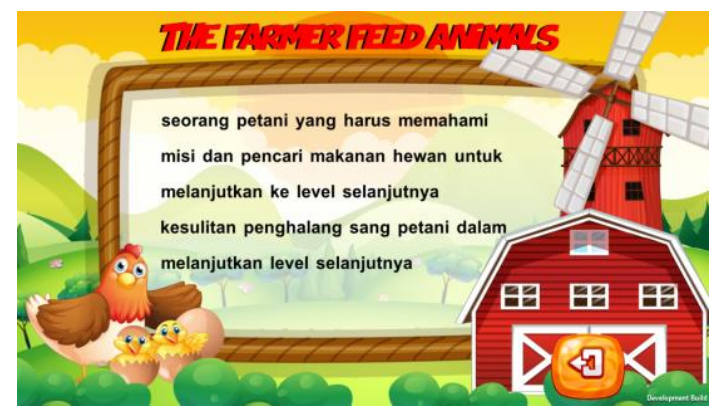

Gambar 4.3 Tampilan Menu Options

\subsection{Tampilan Level 1}

Level 1 dalam game the farmer feed animals dibuat mudah dengan pencarian makanan yang sedikit. Ada pun tampilan game terdapat pada gambar 4.4

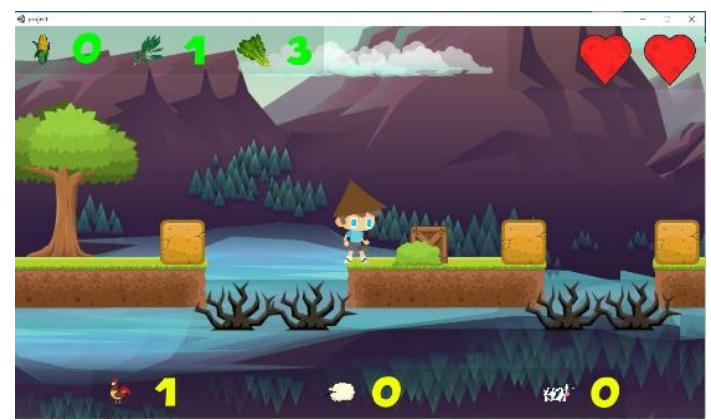

Gambar 4.4 Tampilan Level 1

\subsection{Tampilan Level 1 Complete}

Level 1 dalam game the farmer feed animals dengan jumlah pencarian makanan yang di dapat oleh petani. Adapun tampilan pada gambar 4.5

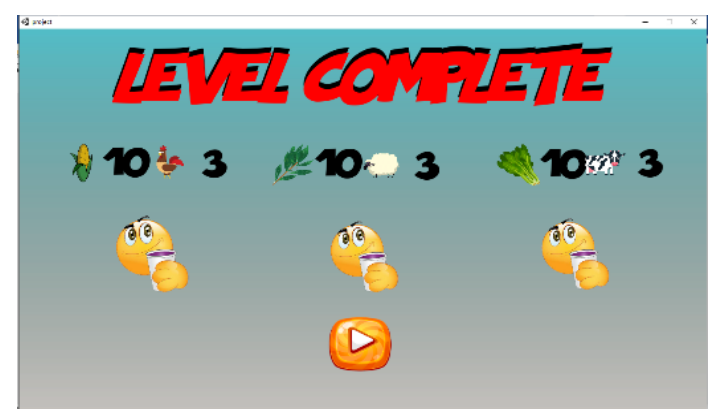

Gambar 4.5 Tampilan Level 1 Complete

\subsection{Tampilan Level 2}

Setelah permain berhasil level 1, maka permain akan diarahkan menuju level 2. pada level 2 ini jumlah makanan lebih banyak pergerakan sedang dan rintangan semakin lebih tambah. Terdapat pada gambar 4.6

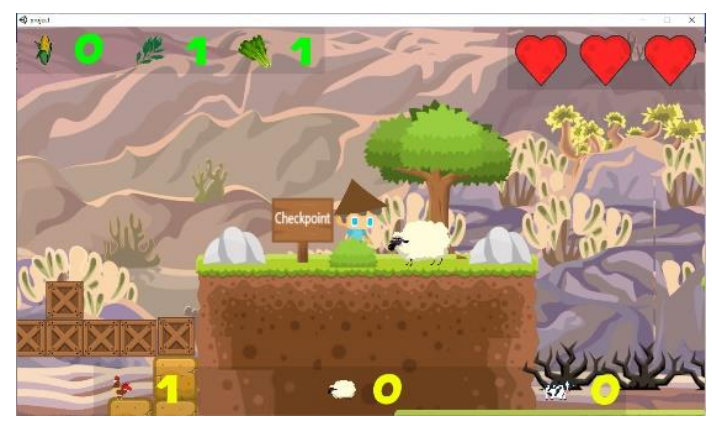

Gambar 4.6 Tampilan Game Level 2

\subsection{Tampilan Level 2 Complete}

Level 2 dalam game the farmer feed animals dengan jumlah pencarian makanan yang di dapat oleh petani. Adapun tampilan pada gambar 4.7

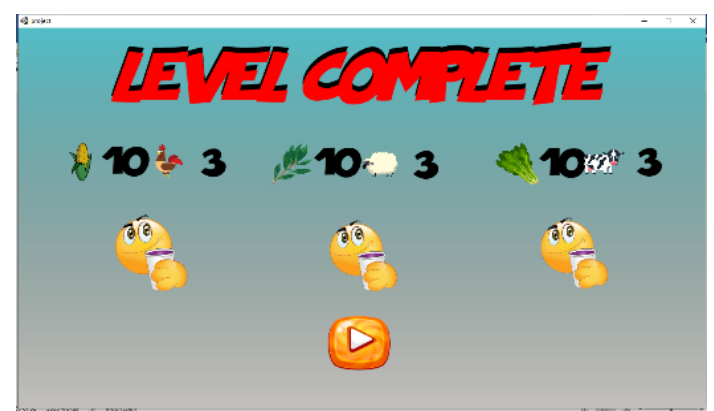

Gambar 4.7 Tampilan Level 2 Complete

\subsection{Tampilan level 3}

Setelah permainan berhasil level 2, permainan akan di arahkan menuju ke level 3. jumlah makanan pada level 3 ini akan lebih banyak dari level sebelumnya untuk mempersulit permainan dan rintangan lebih banyak agar permainan sulit untuk menyelesaikan level ini terdapat pada gambar 4.8 


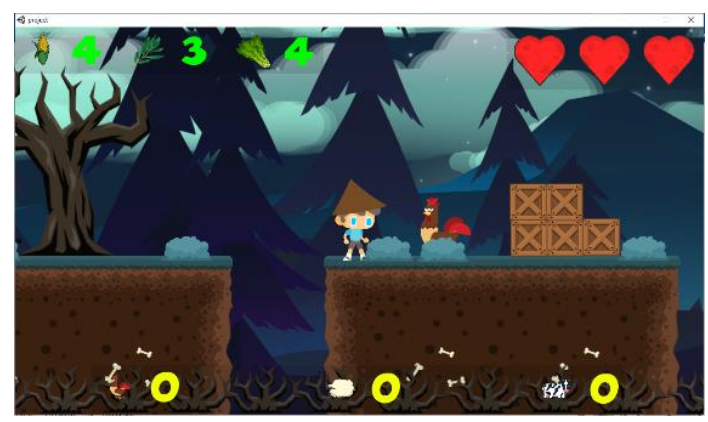

Gambar 4.8 tampilan Game level 3

\subsection{Tampilan Level 3 Complete}

Level 3 dalam game the farmer feed animals dengan jumlah pencarian makanan yang di dapat oleh petani. Adapun tampilan pada gambar 4.9

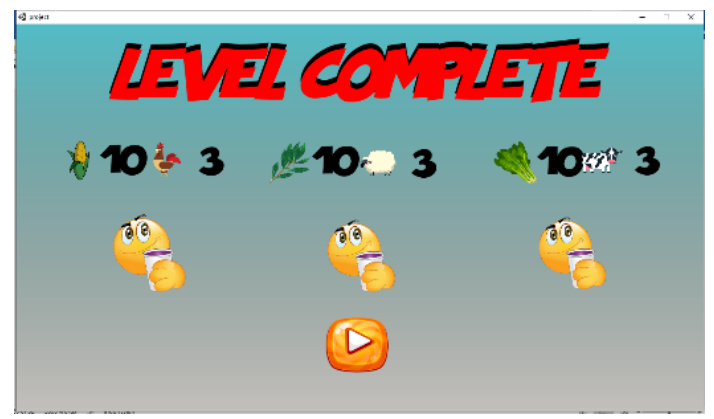

Gambar 4.9 Tampilan Level 3 Complete

\subsection{Tampilan Level 3 Rumah}

Level 3 dalam game the farmer feed animals jika misi sudah selesai maka petani akan kembali pulang ke rumah. Adapun tampilan gambar 4.10

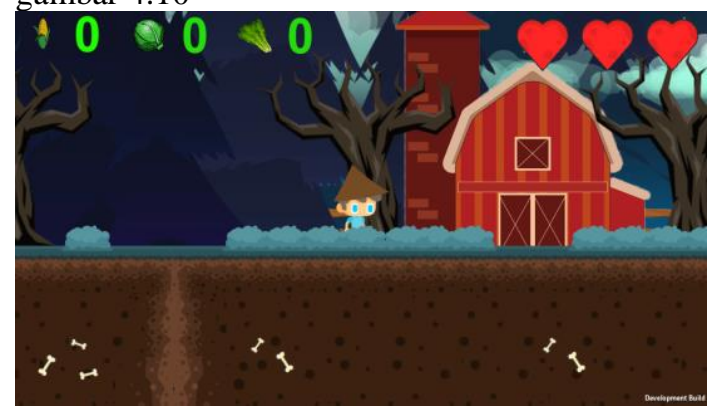

Gambar 4.10 Tampilan Game Level 2

\subsection{Tampilan Play Game}

Dalam game the farmer feed animals jika berhenti bermain maka akan ada tampilan pause atau berhenti dari permainan. Adapun tampilan gambar 4.11

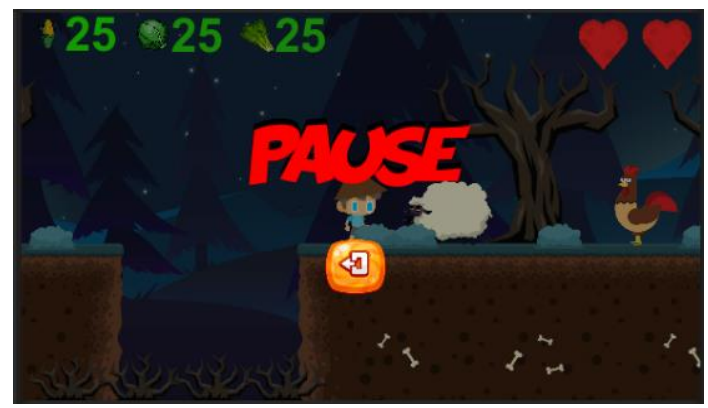

Gambar 4.11 tampilan Pause

\subsection{Pengujian}

Pada tahapan pengujian penulis menampilkan hasil dari pengujian yang telah dilakukan, dimana penguji tersebut meliputi penguji fungsional sistem, apakah semua fungsi dalam game The Farmer Feed Animals telah berfungsi semua atau belum, selanjutnya adalah pengujian terhadap user, apakah game yang dibuat telah memenuhi aspek-aspek yang dikehendaki oleh penulis.

\subsection{Pengujian Penerapan Metode Finite State Machine}

Pengujian penerapan metode Finite State Machine digunakan untuk mengidentifikasi tingkat keberhasilan sistem setelah dijalankan.

Tabel 4.2 Pengujian Penerapan Metode

\begin{tabular}{|c|l|c|c|}
\hline No & \multicolumn{1}{|c|}{ Fungsi } & Berhasil & Gagal \\
\hline 1 & $\begin{array}{l}\text { Interaksi enemy } \\
\text { dengan player }\end{array}$ & $\sqrt{ }$ & - \\
\hline 2 & $\begin{array}{l}\text { Interaksi item } \\
\text { dengan player }\end{array}$ & $\sqrt{ }$ & - \\
\hline 3 & $\begin{array}{l}\text { Interaksi Player } \\
\text { dengan Barrier }\end{array}$ & $\sqrt{ }$ & - \\
\hline 4 & Enemy patrol & $\sqrt{ }$ \\
\hline 5 & Enemy follow & & $\sqrt{ }$ \\
\hline
\end{tabular}

Berdasarkan pengujian penerapan metode pada Tabel 4.2 diketahui bahwa semua fungsi yang terdapat Finite State Machine berjalan dengan baik dan sesuai, dan terdapat fungsi enemy follow yang gagal karena musuh tidak akan mengejar dan tetap di posisi output-nya. 


\subsection{Pengujian Kontrol Player}

Pengujian kontrol player digunakan untuk mengidentifikasi tingkat keberhasilan tombol yang digunakan selama permainan berlangsung. Adapun pengujian kontrol player

\begin{tabular}{|c|c|c|c|}
\hline No & Tombol & Fungsi & Hasil \\
\hline 1 & & $\begin{array}{c}\text { Menggerakkan ke } \\
\text { kiri }\end{array}$ & Sesuai \\
\hline 2 & \multicolumn{1}{c|}{$\begin{array}{c}\text { Menggerakkan ke } \\
\text { kanan }\end{array}$} & Sesuai \\
\hline 3 & Shift & $\begin{array}{c}\text { Menggerakkan ke } \\
\text { atas }\end{array}$ & Sesuai \\
\hline 4 & Menggerakkan & Sesuai \\
\hline
\end{tabular}

Berdasarkan pengujian kontrol player pada Tabel 4.3 diketahui bahwa semua tombol yang pada game sesuai dengan output-nya.

\subsection{Pengujian User}

Pengujian dilakukan untuk mengetahui apakah system sudah berjalan dengan baik atau belum. Pengujian ini menggunakan metode pengumpulan data melalui kuisioner. Pengguna akan mencoba game ini, kemudian pengguna akan memberi feedback pada kuisioner yang telah disediakan.

Untuk mengetahui tanggapan dan penilaian pengguna terhadap game ini. Telah disebarkan kuisioner kepada 10 responden dengan usia berdasarkan pada kebutuhan pengguna. Yang menyatakan baik sebanyak 14\%.yang menyatakan baik sekali $50 \%$ dan yang menyatakan cukup $36 \%$.

\section{KESIMPULAN DAN SARAN}

\subsection{Kesimpulan}

Berdasarkan hasil dari perancangan dan implementasi pada Game shooter platformer maka diambil beberapa kesimpulan sebagai berikut:

1. Sistem menunjukkan bahwa game The Farmer Feed Animals dapat berjalan dengan baik minimal pada Windows 7, Windows 8, dan Windows 10

2. Fungsi yang terdapat Finite State Machine berjalan dengan baik dan sesuai, dan terdapat fungsi enemy follow yang gagal karena musuh tidak akan mengejar dan tetap di posisi output-nya.

3. Semua tombol yang pada game sesuai dengan output-nya.

4. Berdasarkan hasil pengujian koresponden yang menyatakan baik sebanyak $14 \%$.yang menyatakan baik sekali $50 \%$ dan yang menyatakan cukup $36 \%$.

\subsection{Saran}

Adapun saran sebagai acuan terhadap penelitian atau pengembangan selanjutnya, diantaranya :

1. Dapat dikembangkan dalam bentuk multiplayer game.

2. Dapat dikembangkan menjadi game berbasis mobile sehingga dapat dimainkan pada sistem operasi android.

3. Penambah level pada game karena hanya 3 level pada game the farmer feed animals

\section{DAFTAR PUSTAKA}

[1] Jhon (2017). Perancangan dan Pembuatan Game Edukasi Right Thinking Dengan Metode Greedy. Kisaran Sumatra Utara: Universitas Sumatera Utara, Fakultas Teknik UNA.

[2] Ekawati (2019) "Penerapan Metode Finite State Machine (FSM) pada Game Agent Legenda Anak Borneo", Sebatik, 23(1), pp. 116-123.

[3] Zulfahmi (2016) Passion Be Engineer Blog Mahasiswa Universitas Brawijaya.

[4] Mifta (2016) Penerapan metode Finite State Machine pada Game "The Relationship ejournals.

[5] Erwin (2013) Game Edukasi berbasis Role Playing Game dengan Metode Finite State Machine.

[6] Gustav (2018) Game "2 Snakes dan Pong dengan efek suara"

[7] Adityo (2019) menjadikan "game sebagai metode pendidikan"

[8] Edy (2016) Rancang bangun game adventure Gryo berbasis android menggunakan model rational unified process (RPU)

[9] Marliana (2015) Hakkajiten.wordpress. index. pengantar teori game

[10] Antonius (2011) Chichungunya.wordpress. com.definisi game 